\title{
Redescription of Lutzomyia (Lutzomyia) souzalopesi Martins, Silva \& Falcão, 1970 (Diptera, Psychodidae, Phlebotominae)
}

\author{
Edelberto Santos Dias ${ }^{+}$, José Dilermando Andrade Filho, \\ Alda Lima Falcão
}

\begin{abstract}
Laboratório de Leishmanioses, Centro de Pesquisas René Rachou-FIOCRUZ, Av. Augusto de Lima 1715, 30190-002 Belo Horizonte, MG, Brasil
\end{abstract}

The authors redescribe the male and the female of Lutzomyia (Lutzomyia) souzalopesi Martins, Silva \& Falcão, 1970. Taxonomic remarks, geographic distribution and drawings are presented.

Key words: Lutzomyia souzalopesi - sand fly - phlebotominae

Lutzomyia souzalopesi was first described by Martins et al. (1970) when examining a lot of phlebotomines collected at São José, municipality of Aracruz, State of Espírito Santo, Brazil. The species was named after the entomologist and friend Prof. Hugo de Souza Lopes from the Instituto Oswaldo Cruz, Rio de Janeiro, RJ, Brazil.

In this study, we re-examined a number of $L$. souzalopesi specimens from the reference collection of sand flies at the Centro de Pesquisas René Rachou, including the type material. As discrepancies were found relative to the original description, we decided to repeat the morphometry of the type series and to describe, in more detail, certain fundamental structures for the identification of $L$. souzalopesi.

\section{Lutzomyia (Lutzomyia) souzalopesi Martins, Falcão \& Silva \\ (Fig.1: a-f ; Fig. 2: a-i)}

Holotype male (measurements in $\mathrm{mm}$ ). Sand fly length 3.0. Head length 0.252 long, 0.368 wide. Clypeus 0.124 long. Head:clypeus ratio 2.0:1. Eyes separated by 0.104 . Labrum, measured from the distal margin of the clypeus 0.235 . Lengths of flagellomeres: I - 0.349, II - 0.169, III - 0.158, IV $-0.158, \mathrm{~V}-0.148, \mathrm{VI}-0.144$, VII - 0.138, VIII 0.131, IX - 0.128, X-0.121, XI - 0.110, XII - 0.100, XIII - 0.863, XIV - 0.794. Ratio between length of flagellomere I: length of labrum 1.5:1. Total palpal length 0.818. Lengths of palpomeres: $1-0.041$, 2 - 0.142, 3 - 0.176, 4 - 0.128, 5 - 0.331. Palpal formula 1.4.2.3.5, with palpomere 5 longer than 2 +3 . Thorax partially infuscated with transparent

${ }^{+}$Corresponding author. Received 30 June 1995 Accepted 9 November 1995
pleuras.Wing length 2.147, maximum width 0.597 , ratio of wing length and maximum width 3.598:1. Lengths of wing sections: R2 (alpha) - 0.593, R2 + 3 (beta) - 0.224, R2 + $3+4$ (gamma) - 0.193, R1 tip (delta) - 0.214. Ratio alpha:beta 2.6:1. Legs without special characters. Abdomen 2.300 long including coxite. Coxite 0.349 long, maximum width 0.079 , with basal tuft of 5 setae, two slender and 3 broad inserted on a raspberry-like tubercle. Style 0.214 long, with paired median spines, 1 isolated spine and 1 terminal spine, subterminal seta present. Paramere with most dorsal setae on the distal third, two spines implanted on the dorsal surface. Lateral lobe 0.362 long. Aedeagus 0.107 long, well pigmented, shaped as shown. Genital pump 0.169 long, each filament 0.724 long or 4.284X the length of pump; filament tips simple.

Paratype female. Sand fly length 3.0. Head heigth including clypeus 0.297 long, 0.455 wide. Clypeus 0.135 long. Head: clypeus ratio 2.204:1. Eyes separated by 0.114 . Labrum, measured from the distal margin of the clypeus 0.242 long. Lengths of flagellomeres: I - 0.359; II - 0.159; III - 0.162; IV - 0.152; V - 0.145; VI - 0.142; VII - 0.124; VIII -0.124 ; IX - 0.121; X - 0.114. Last segments missing. Ratio between length of flagellomere I: length of labrum 1.5:1. Total palpal length 0.817. Lengths of palpomeres: $1-0.048 ; 2-0.138 ; 3-0.176 ; 4$ $0.110 ; 5-0.345$. Palpal formula 1.4.2.3.5, with palpomere 5 longer than $3+4$. Cibarium with ten irregular horizontal teeth and one row of vertical teeth; pigment patch poorly defined; cibarial arch incomplete. Thorax partially infuscated. Wing length 2.344 , maximum width 0.613 , ratio between wing length and maximum width $3.827: 1$. Lengths of wing sections: R2 (alpha) - 0.586; R2+3 (beta) $0.210 ; \mathrm{R} 2+3+4$ (gamma) - 0.311; R1 tip (delta) - 0.201. Ratio alpha:beta 2.8:1. Legs without special characters. Abdomen 2.125 long. Body of the 


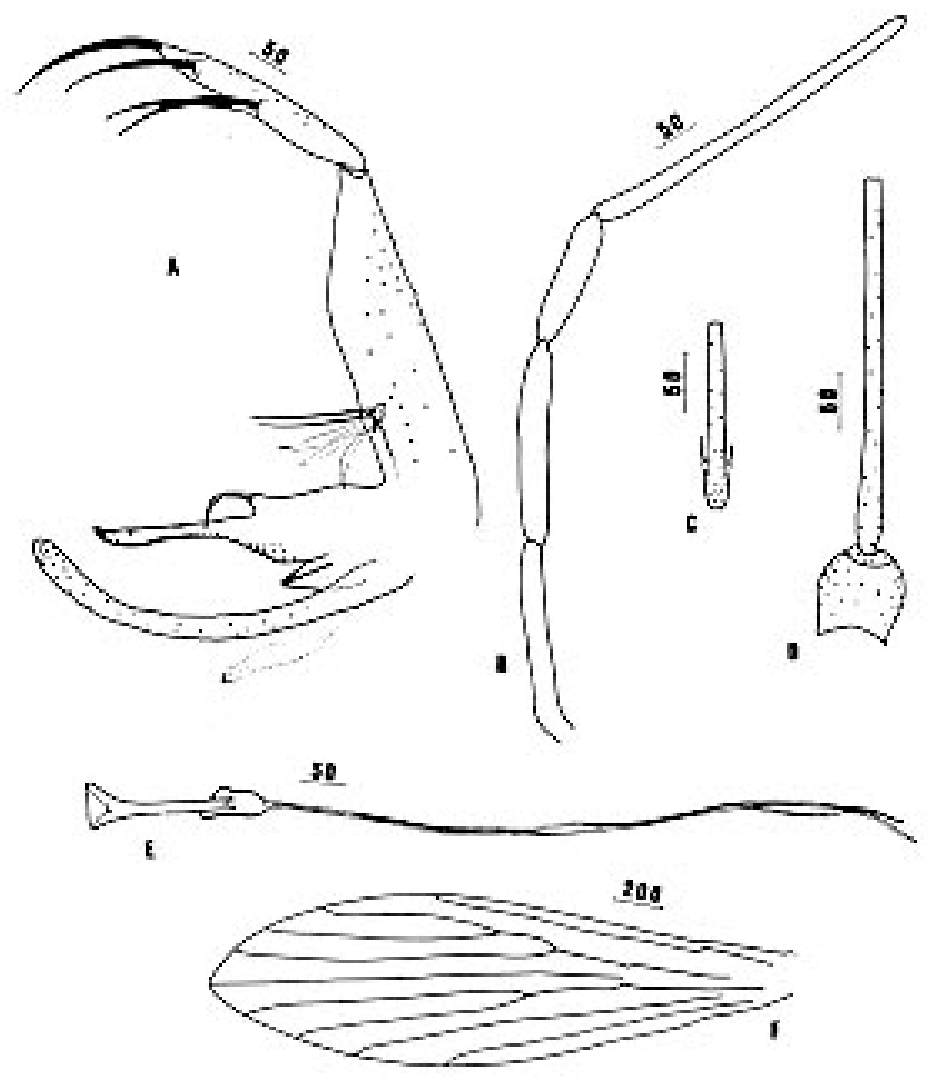

Lutzomyia (Lutzomyia) souzalopesi (holotype male slide no. 35792 A) Fig 1-A: genitalia. B: palp. C: flagellomere II showing ascoids. D: flagellomere I. E: genital pump. F: wing. (measurements in micra).

spermatheca elongated, weakly annulated with about 12 segments; body of the spermatheca continuous with its duct; individual spermathecal duct long.

Type material - Holotype male (35.792 A) and paratype female (35.792 B) were collected from tree trunks at São José, municipality of Aracruz, State of Espírito Santo in May 14, 1965 (JE Silva $\&$ J Ribeiro cols). The type material includes also one paratype male and two paratypes females (slides no. $35.792 \mathrm{C}-\mathrm{E}$ ). Moreover, six males and three females collected in the Reserva Florestal de Soretama, municipality of Linhares, State of Espírito Santo in 01/20-26/82, with Damasceno trap (JE Silva col.) were examined. The holotype and paratypes (no.35.792 C-E) are deposited in the reference collection of sand flies at the Centro de Pesquisas René Rachou, Fundação Oswaldo Cruz, Belo Horizonte, MG, Brazil.

\section{REMARKS}

Undoubtedly, L. souzalopesi belongs to the longipalpis group (Theodor 1965), currently in the subgenus Lutzomyia (Martins et al. 1978, Young \& Duncan 1994). According to the original description (Martins et al. 1970) "the male is easily distinguished from other species in the group by the elongated aspect of the genitalia, the size relatively reduced of the spines of the paramere and, mainly, by the length of the genital filaments and by the basal tuft constituted by broad leaf-like hairs, similar to Lutzomyia (Lutzomyia) cruzi (Mangabeira 1942). The female can be distinguished by the shape of the spermatheca, by the elementary cibarium and by the length of the spermatheca ducts".

When comparing females from the subgenus Lutzomyia, L. cruzi and L. longipalpis are the most similar to L. souzalopesi. However, L. souzalopesi can be easily distinguished by the much longer length of the cercus (Fig. $2 \mathrm{f}$ ).

After examining the type material, we verified that the tuft of hairs on the basistyle of the male of L. souzalopesi is, in fact, constituted by five setae, two long and slender plus three broad and flexible, instead of four leaf-like setae as originally described (Martins et al. 1970). Besides, in the original description, the authors reported that the 
TABLE

Measurements of some morphological characters of Lutzomyia souzalopesi specimens

\begin{tabular}{|c|c|c|c|c|c|}
\hline \multirow[t]{2}{*}{ Characters } & & \multicolumn{2}{|l|}{ Male } & \multicolumn{2}{|l|}{ Female } \\
\hline & & Mean \pm s.d. $(\mathrm{mm})$ & $\mathrm{n}$ & Mean \pm s.d. $(\mathrm{mm})$ & $\mathrm{n}$ \\
\hline Head length & & $0.269 \pm 0.019$ & 7 & $0.285 \pm 0.021$ & 5 \\
\hline Head width & & $0.362 \pm 0.016$ & 5 & $0.399 \pm 0.019$ & 4 \\
\hline Clypeus & & $0.121 \pm 0.009$ & 7 & $0.285 \pm 0.013$ & 5 \\
\hline Eyes diameter & & $0.143 \pm 0.013$ & 6 & $0.145 \pm 0.021$ & 4 \\
\hline Interocular distance & & $0.090 \pm 0.010$ & 5 & $0.109 \pm 0.003$ & 6 \\
\hline Labrum length & & $0.230 \pm 0.008$ & 8 & $0.251 \pm 0.012$ & 6 \\
\hline Palpal length & 1 & $0.041 \pm 0.003$ & 8 & $0.044 \pm 0.006$ & 6 \\
\hline & 2 & $0.132 \pm 0.009$ & 8 & $0.139 \pm 0.008$ & 6 \\
\hline & 3 & $0.162 \pm 0.013$ & 8 & $0.173 \pm 0.014$ & 6 \\
\hline & 4 & $0.112 \pm 0.012$ & 8 & $0.121 \pm 0.008$ & 5 \\
\hline & 5 & $0.307 \pm 0.025$ & 7 & $0.337 \pm 0.002$ & 4 \\
\hline Flagellomeres & I & $0.361 \pm 0.021$ & 8 & $0.361 \pm 0.033$ & 6 \\
\hline & II & $0.170 \pm 0.014$ & 8 & $0.174 \pm 0.011$ & 6 \\
\hline & III & $0.167 \pm 0.013$ & 8 & $0.175 \pm 0.012$ & 5 \\
\hline & IV & $0.160 \pm 0.010$ & 8 & $0.165 \pm 0.012$ & 5 \\
\hline & $\mathrm{V}$ & $0.152 \pm 0.012$ & 8 & $0.153 \pm 0.015$ & 5 \\
\hline & VI & $0.143 \pm 0.009$ & 8 & $0.149 \pm 0.015$ & 5 \\
\hline & VII & $0.136 \pm 0.010$ & 8 & $0.138 \pm 0.014$ & 5 \\
\hline & VIII & $0.123 \pm 0.010$ & 8 & $0.132 \pm 0.011$ & 5 \\
\hline & IX & $0.121 \pm 0.009$ & 8 & $0.131 \pm 0.010$ & 5 \\
\hline & $\mathrm{X}$ & $0.113 \pm 0.009$ & 8 & $0.117 \pm 0.004$ & 3 \\
\hline & XI & $0.108 \pm 0.005$ & 8 & $0.125 \pm 0.005$ & 2 \\
\hline & XII & $0.097 \pm 0.013$ & 7 & $0.106 \pm 0.002$ & 2 \\
\hline & XIII & $0.081 \pm 0.008$ & 6 & $0.083 \pm 0.000$ & 2 \\
\hline & XIV & $0.078 \pm 0.005$ & 6 & $0.073 \pm 0.000$ & 2 \\
\hline Thorax length & & $0.556 \pm 0.024$ & 8 & $0.621 \pm 0.049$ & 5 \\
\hline Wing length & & $2.149 \pm 0.072$ & 8 & $2.362 \pm 0.087$ & 6 \\
\hline Wing width & & $0.570 \pm 0.032$ & 8 & $0.645 \pm 0.060$ & 6 \\
\hline Alpha & & $0.571 \pm 0.028$ & 7 & $0.659 \pm 0.060$ & 6 \\
\hline Beta & & $0.205 \pm 0.022$ & 7 & $0.236 \pm 0.010$ & 6 \\
\hline Gamma & & $0.252 \pm 0.045$ & 7 & $0.271 \pm 0.032$ & 6 \\
\hline Delta & & $0.219 \pm 0.031$ & 7 & $0.263 \pm 0.042$ & 6 \\
\hline Abdomen length & & $2.127 \pm 0.197$ & 8 & $2.216 \pm 0.162$ & 6 \\
\hline Genital pump & & $0.153 \pm 0.014$ & 8 & & \\
\hline Pump length & & $0.128 \pm 0.013$ & 8 & & \\
\hline Genital filament & & $0.699 \pm 0.027$ & 8 & & \\
\hline Aedeagus & & $0.102 \pm 0.009$ & 8 & & \\
\hline Lateral lobe length & & $0.375 \pm 0.022$ & 8 & & \\
\hline Lateral lobe width & & $0.025 \pm 0.002$ & 8 & & \\
\hline Paramere length & & $0.311 \pm 0.008$ & 8 & & \\
\hline Paramere width & & $0.056 \pm 0.005$ & 8 & & \\
\hline Coxite length & & $0.342 \pm 0.012$ & 8 & & \\
\hline Coxite width & & $0.081 \pm 0.004$ & 8 & & \\
\hline Style length & & $0.210 \pm 0.005$ & 8 & & \\
\hline Style width & & $0.032 \pm 0.002$ & 8 & & \\
\hline Cercus & & & & $0.306 \pm 0.014$ & 6 \\
\hline Spermathecae length & & & & $0.048 \pm 0.000$ & 1 \\
\hline Spermathecae width & & & & $0.012 \pm 0.000$ & 1 \\
\hline
\end{tabular}



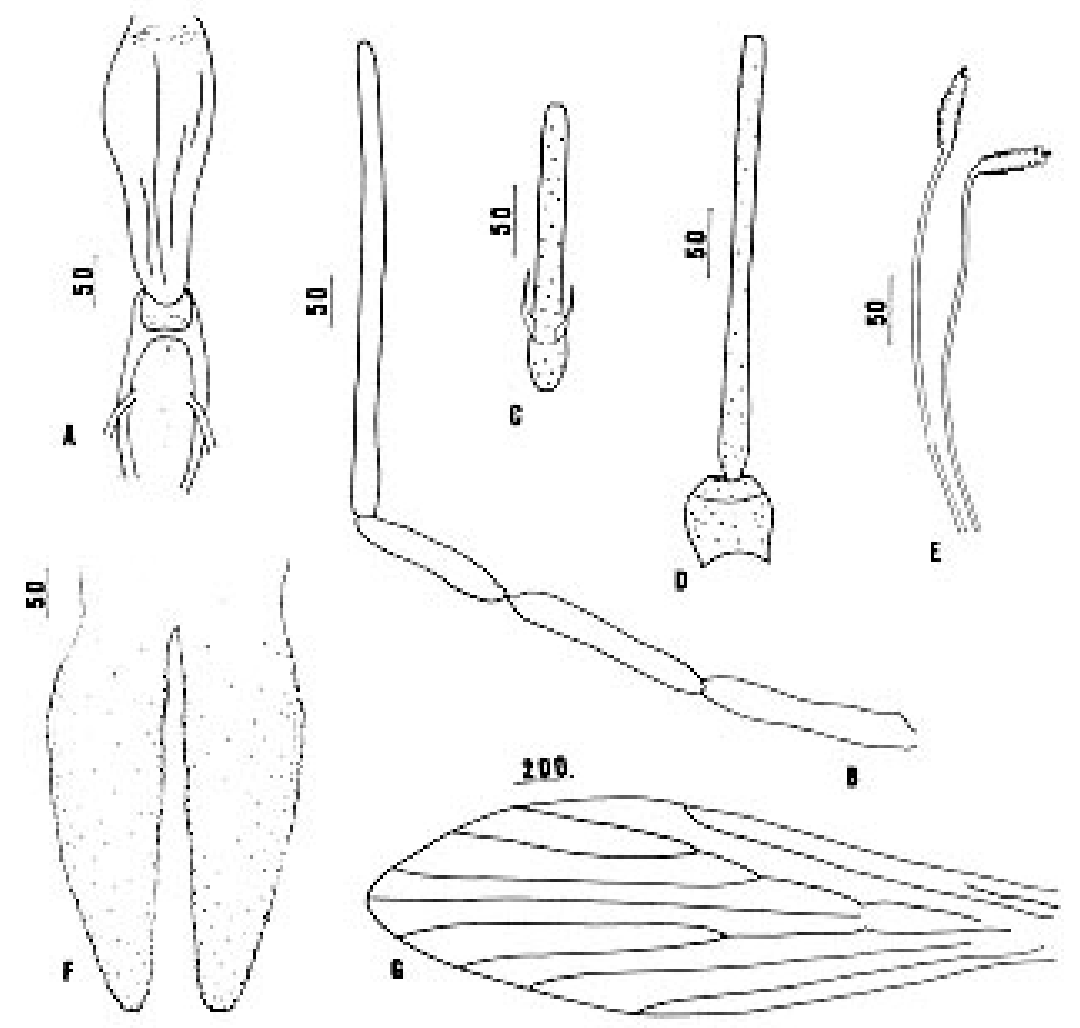

Lutzomyia (Lutzomyia) souzalopesi (paratype female slide no. 35792 B) Fig 2-A: cibarium. B: palp. C: spermathecae. D: flagellomere II showing ascoids. E: flagellomere I. F: cercus. G: cercus of $L$. cruzi. H: cercus of L. longipalpis. I:wing. (measurements in micra).

last two flagellomeres were missing in the holotype male. After reexamining the holotype male, we verified that those segments are present.

The distinction between the male of $L$. souzalopesi and males from other species in the subgenus can be easily made not only by the number but also by the characteristics of the tuft of hair on basistyle: broad and leaf-like, two longer and two shorter in L. cruzi (Mangabeira 1938); slender, hair-like, all four with equal length in L. longipalpis (Lutz \& Neiva 1912). L. souzalopesi has a restricted distribution and has not been implicated as a vector of Leishmania species.

\section{REFERENCES}

Martins AV, Silva JE, Falcão AL 1970. Lutzomyia (Lutzomyia) souzalopesi $\mathrm{sp}$. n., nova espécie de flebótomo do Estado do Espírito Santo (Diptera, Psychodidae, Phlebotominae). Mem Inst Oswaldo Cruz 30: 559-562.

Martins AV, Williams P, Falcão AL 1978. American Sandflies. Acad Bras Cienc, Rio de Janeiro, 195 pp.

Theodor O 1965. On the classification of the American Phlebotominae. J Med Ent 2: 171-197.

Young DG, Duncan MA 1994. Guide to the Identification and Geographic Distribution of Lutzomyia Sand Flies In Mexico, the West Indies, Central and South America (Diptera: Psychodidae), Mem Amer Ent Inst $54,881 \mathrm{pp}$. 